\title{
Maintenance of the Remission Stage of Crohn's Disease with Adalimumab Therapy during Pregnancy
}

Tsutomu Mizoshita, Satoshi Tanida, Hironobu Tsukamoto, Keiji Ozeki, Takahito Katano, Masahide Ebi, Yoshinori Mori, Hiromi Kataoka, Takeshi Kamiya and Takashi Joh

\begin{abstract}
A 25-year-old pregnant woman complained of abdominal pain and diarrhea. Total colonoscopy provided a diagnosis of Crohn's disease (CD) of the large intestine (Crohn's colitis). Because the patient was allergic to mesalazine, adalimumab (ADA) was used as maintenance therapy during pregnancy, following prednisolone as remission induction therapy. Remission of the patient's CD was maintained with ADA, and the patient delivered a baby girl without any difficulties. Remission of the patient's CD continued to be maintained with the administration of ADA after childbirth. We believe that this is the first report of the use of ADA therapy in a pregnant CD patient in Japan.
\end{abstract}

Key words: Crohn's disease, pregnancy, adalimumab, intensive granulocyte and monocyte adsorptive apheresis

(Intern Med 52: 1049-1053, 2013)

(DOI: 10.2169/internalmedicine.52.9466)

\section{Introduction}

Crohn's disease (CD) is a chronic inflammatory bowel disorder, with no currently established curative therapies (1). At present, the pharmacologic management of $\mathrm{CD}$ is accomplished with 5-aminosalicylic acid (5-ASA) drugs, corticosteroids, immunomodulators (i.e., azathioprine and 6mercaptopurine (6-MP)), antibiotics and tumor necrosis factor (TNF)- $\alpha$ blockers (2). Treatment with anti-TNF- $\alpha$ antibodies such as infliximab (IFX) and adalimumab (ADA, a fully human monoclonal IgG1 antibody) can induce mucosal healing in the affected parts of the digestive tract and dramatically change a patient's clinical history of $\operatorname{CD}(2,3)$. ADA has been proven to be a very useful therapeutic agent for the treatment of $\mathrm{CD}(2,4)$. ADA is effective and welltolerated for the induction and maintenance of clinical remission in Japanese patients with moderate to severe CD (5). In addition, granulocyte and monocyte adsorptive apheresis (GMA) (Adacolumn ${ }^{\circledR}$; JIMRO Co., Ltd., Takasaki, Gunma, Japan) is another effective therapeutic option for treating refractory inflammatory bowel diseases (IBD) such as $\mathrm{CD}$ and ulcerative colitis (UC) $(2,6,7)$.
During pregnancy, therapeutic options are limited due to concerns for the safety of the fetus (8). According to previous reports by the United States Food and Drug Administration (FDA) (http://www.fda.gov/Drugs/DevelopmentApprova 1Process/DevelopmentResources/Labeling/ucm093307.htm), 5-ASA, corticosteroids and GMA have been proven safe and are recommended for use during pregnancy $(8,9)$. However, the safety of GMA during pregnancy remains unclear in patients with IBD because there are no meta-analysis reports of exposure to GMA during pregnancy. ADA, a pregnancy category B drug, is also an IgG1 antibody and should therefore have a placental transfer rate similar to that of IFX (10).

We herein report the case of a pregnant patient with CD who was successfully treated with ADA maintenance therapy following corticosteroids, received intensive GMA therapy for inhibition of flaring and delivered a baby girl without any congenital malformations or neurological abnormalities.

\section{Case Report}

A 25-year-old pregnant woman complained of abdominal 


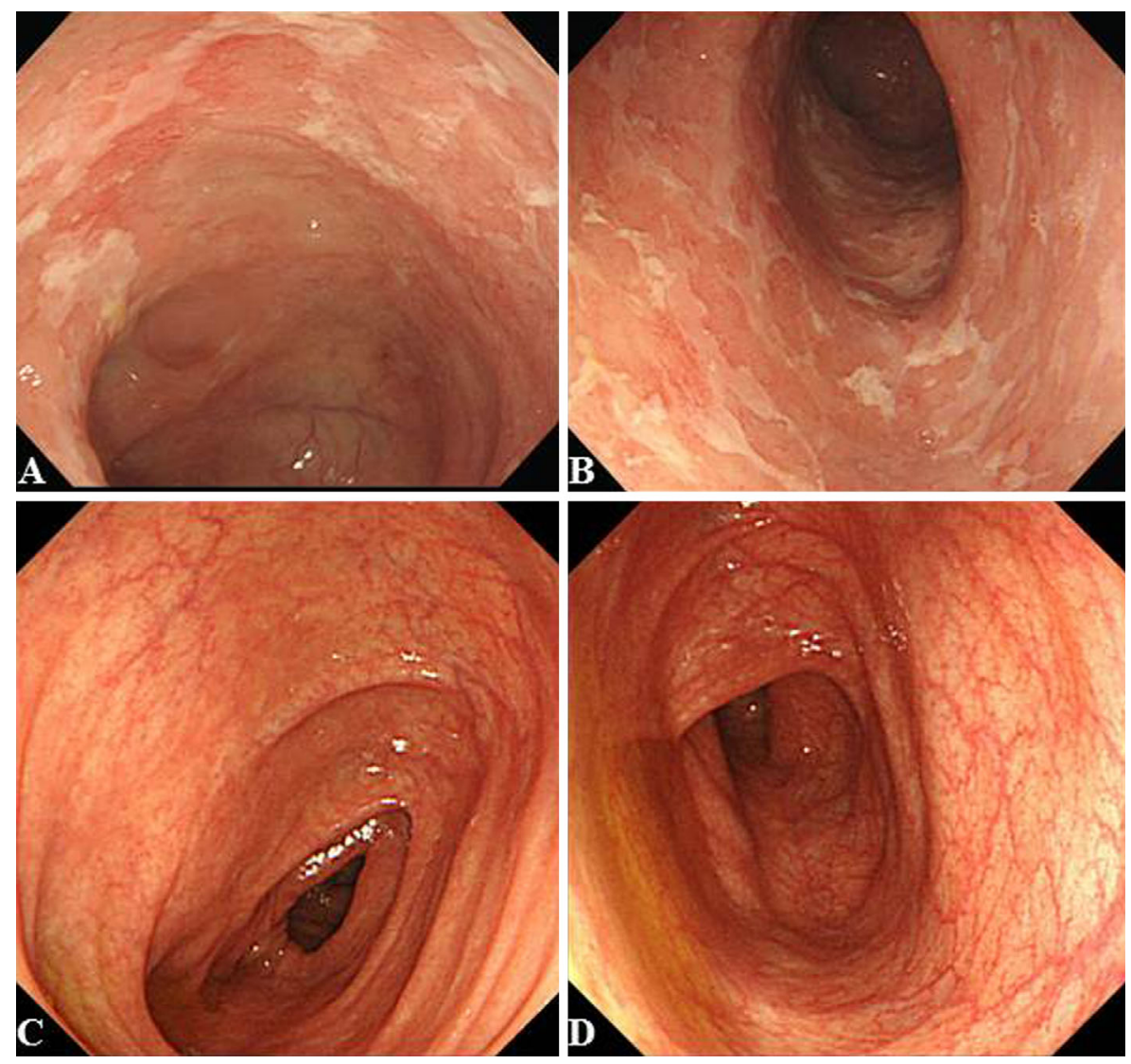

Figure 1. Colonoscopy performed before therapy showed serpiginous (snake-like) ulcers in the transverse colon (A and B). Colonoscopy performed after 14 months of adalimumab therapy showed mucosal healing of the inflammatory lesions in the transverse colon (C and D).

pain and diarrhea occurring more than 10 times a day. She had a clinical history of an anal fistula that had been cured. Total colonoscopy performed in June 2011 revealed serpiginous (snake-like) ulcers in the large intestine extending from the ascending colon to the transverse colon. No lesions were detected in the ileocecum, descending colon, sigmoid colon or rectum. No bacterial or viral infections were detected on stool culture or hemodiagnosis. The patient was diagnosed with CD of the large intestine (Crohn's colitis) in July 2011 according to the Japanese diagnostic criteria for $\mathrm{CD}$, although there were no specific pathological findings of $\mathrm{CD}$, such as granulomas, in the biopsy samples of the ulcer lesions. In August 2011, therapy was initiated with oral mesalazine (5-ASA, 3,000 mg/day, Pentasa ${ }^{\circledR}$ ). However, immediately after the mesalazine therapy was started, the patient complained of systemic arthralgia, particularly in the knees, suggesting an adverse event of the drug. The mesalazine therapy was discontinued, and the systemic arthralgia improved instantly. In September 2011, the patient was admitted to our hospital for treatment due to worsening of abdominal pain and diarrhea after stopping the mesalazine.

At the time of presentation, the patient's laboratory results were as follows: white blood cells (WBC), 8,900/ $\mu \mathrm{L}(3,000 /$ $\mu \mathrm{L} \leq$ normal range $\leq 8,500 / \mu \mathrm{L}$ ); C-reactive protein (CRP), $2.52 \mathrm{mg} / \mathrm{dL}$ (normal range $\leq 0.30 \mathrm{mg} / \mathrm{dL}$ ); erythrocyte sedimentation rate $(\mathrm{ESR}), 40 \mathrm{~mm} / \mathrm{h}$ (normal range $\leq 16 \mathrm{~mm} / \mathrm{h}$ ); red blood count (RBC), $481 \times 10^{4} / \mu \mathrm{L}\left(378 \times 10^{4} / \mu \mathrm{L} \leq\right.$ normal range $\left.\leq 499 \times 10^{4} / \mu \mathrm{L}\right)$; hemoglobin $(\mathrm{Hb}), 10.5 \mathrm{~g} / \mathrm{dL}(10.8 \mathrm{~g} / \mathrm{dL}$ $\leq$ normal range $\leq 14.9 \mathrm{~g} / \mathrm{dL})$; hematocrit $(\mathrm{Ht}), 34.6 \%(35.6 \%$ $\leq$ normal range $\leq 45.4 \%$ ); albumin, $4.3 \mathrm{~g} / \mathrm{dL}(4.0 \mathrm{~g} / \mathrm{dL} \leq$ normal range $\leq 5.0 \mathrm{~g} / \mathrm{dL})$; platelet (Plt), $468 \times 10^{3} / \mu \mathrm{L}\left(150 \times 10^{3} /\right.$ $\mu \mathrm{L} \leq$ normal range $\left.\leq 361 \times 10^{3} / \mu \mathrm{L}\right)$; aspartate amino transferase (AST), $13 \mathrm{U} / \mathrm{L}$ (13 U/L $\leq$ normal range $\leq 33 \mathrm{U} / \mathrm{L})$; alanine transaminase (ALT), $8 \mathrm{U} / \mathrm{L}(6 \mathrm{U} / \mathrm{L} \leq$ normal range $\leq 27 \mathrm{U} / \mathrm{L})$; $\gamma$-glutamyl transpeptidase $(\gamma$-GTP), $10 \mathrm{U} / \mathrm{L}(10 \mathrm{U} / \mathrm{L} \leq$ normal range $\leq 47 \mathrm{U} / \mathrm{L})$; blood urea nitrogen $(\mathrm{BUN}), 8 \mathrm{mg} / \mathrm{dL}(8$ $\mathrm{mg} / \mathrm{dL} \leq$ normal range $\leq 22 \mathrm{mg} / \mathrm{dL}$ ); creatinine (Cre), $0.5 \mathrm{mg}$ / $\mathrm{dL}(0.4 \mathrm{mg} / \mathrm{dL} \leq$ normal range $\leq 0.7 \mathrm{mg} / \mathrm{dL})$; total bilirubin (T.Bil), $0.5 \mathrm{mg} / \mathrm{dL}(0.3 \mathrm{mg} / \mathrm{dL} \leq$ normal range $\leq 1.2 \mathrm{mg} / \mathrm{dL})$; total cholesterol, $202 \mathrm{mg} / \mathrm{dL}(128 \mathrm{mg} / \mathrm{dL} \leq$ normal range $\leq$ $219 \mathrm{mg} / \mathrm{dL})$; triglyceride (TG), $94 \mathrm{mg} / \mathrm{dL}(30 \mathrm{mg} / \mathrm{dL} \leq$ normal range $\leq 149 \mathrm{mg} / \mathrm{dL})$; natrium $(\mathrm{Na}), 138 \mathrm{mEq} / \mathrm{L}(138$ $\mathrm{mEq} / \mathrm{L} \leq$ normal range $\leq 146 \mathrm{mEq} / \mathrm{L})$; potassium $(\mathrm{K}), 4.2$ $\mathrm{mEq} / \mathrm{L}(3.6 \mathrm{mEq} / \mathrm{L} \leq$ normal range $\leq 4.9 \mathrm{mEq} / \mathrm{L})$; chlorine (Cl), $103 \mathrm{mEq} / \mathrm{L}(99 \mathrm{mEq} / \mathrm{L} \leq$ normal range $\leq 109 \mathrm{mEq} / \mathrm{L})$ and calcium $(\mathrm{Ca}), 10.2 \mathrm{mEq} / \mathrm{L}(8.7 \mathrm{mEq} / \mathrm{L} \leq$ normal range $\leq$ $10.3 \mathrm{mEq} / \mathrm{L}$ ) (Table). The CD activity index (CDAI) was 245. Serpiginous ulcers were detected endoscopically in the large intestine extending from the ascending colon to the transverse colon (Fig. 1A, B). No lesions were detected in the ileocecum, descending colon, sigmoid colon or rectum. No bacterial or viral infections were detected on stool cul- 


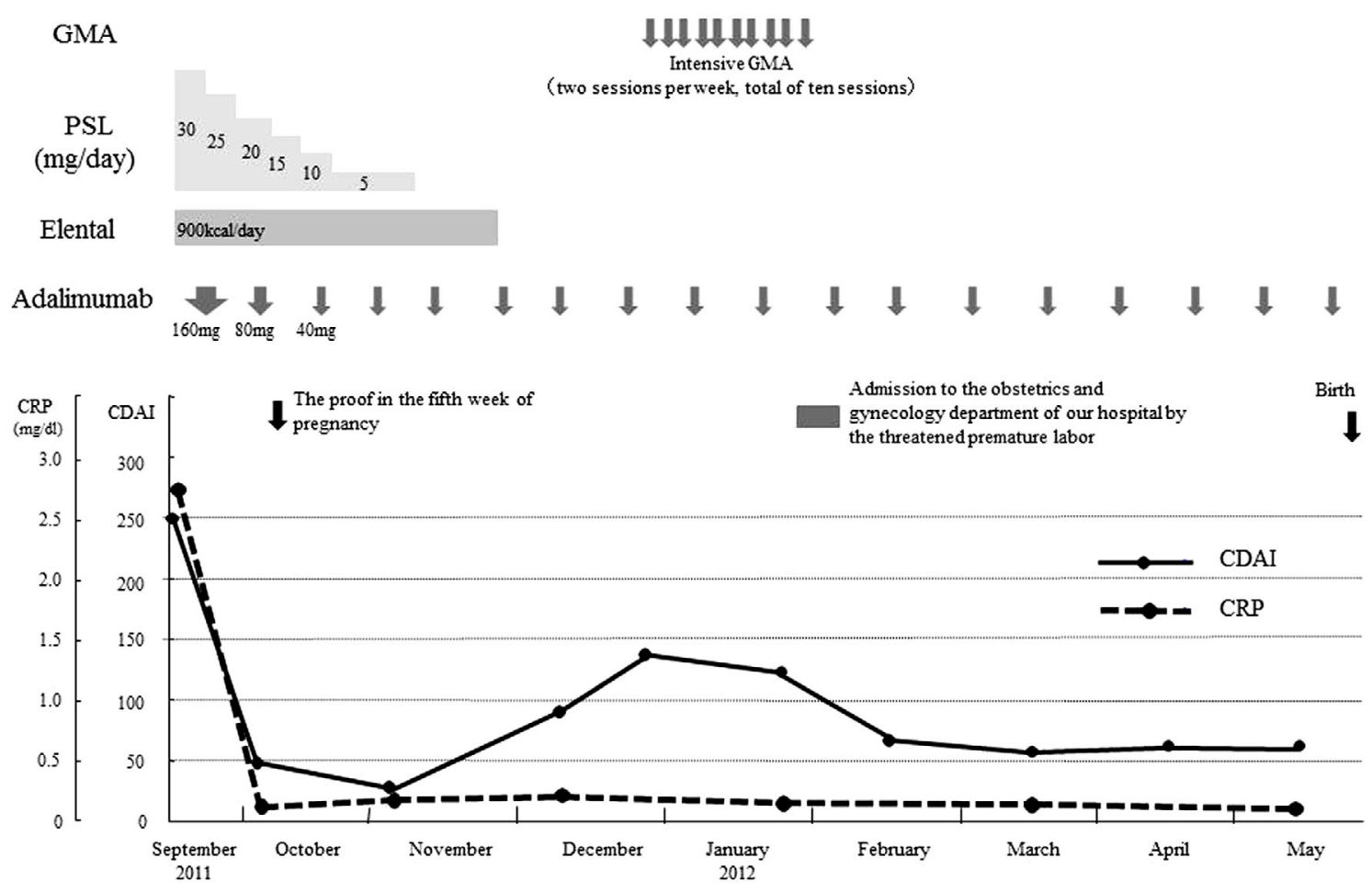

Figure 2. The changes in the Crohn's disease activity index (CDAI) and C-reactive protein (CRP) level from the start of therapy until childbirth.

ture or hemodiagnosis. We diagnosed the patient with the active stage of $\mathrm{CD}$ (large intestine type) and started prednisolone (PSL, $30 \mathrm{mg} /$ day) as remission induction therapy after informed consent was obtained from the patient and her mother (Fig. 2). We also started an elemental diet (ED, 900 kcal/day of Elental ${ }^{\circledR}$, Ajinomoto Pharmaceutical Co. Ltd., Tokyo, Japan) for enteral nutrition (Fig. 2). Because the patient's abdominal condition improved with the administration of PSL, we began to reduce the dose of PSL one week after the initiation of the above-mentioned therapy. In addition to the PSL therapy, we also started ADA, a TNF inhibitor, as maintenance therapy after informed consent was obtained from the patient and her mother (Fig. 2). According to the Japanese protocol, the patient received subcutaneous administration of $160 \mathrm{mg}$ at week 0 and $80 \mathrm{mg}$ at week 2 and subsequent subcutaneous administration of $40 \mathrm{mg}$ as the maintenance dose every other week thereafter. In October 2011, the patient proved to be in the fifth week of pregnancy (Fig. 2). The CDAI decreased from 245 to 28 after two months of PSL and adalimumab therapy. Therefore, we stopped the PSL while continuing ADA. In November 2011, the patient stopped the ED without permission. In December 2011, she presented with an exacerbation of abdominal pain and diarrhea, and we started intensive GMA therapy (two sessions per week for a total of 10 sessions) in addition to ADA, which improved the patient's abdominal symptoms (Fig. 2). In February 2012, the patient was diagnosed with threatened premature labor and was admitted to the obstetrics and gynecology department of our hospital for treatment. Her condition improved as a result of the medication and one week of bed rest (Fig. 2). In May 2012, the pa- tient's first baby was delivered at 39 weeks and two days (female, birth weight: $3,020 \mathrm{~g}$, length: $51 \mathrm{~cm}$ ) without any congenital malformations or neurological abnormalities (Fig. 2). The ADA therapy was continued to maintain the remission stage of CD after childbirth. In November 2012, a second endoscopy showed mucosal healing of the colonic inflammatory lesions (Fig. 1C, D). As of December 2012, remission has been maintained with ADA (40 mg, every other week).

\section{Discussion}

We treated a patient with CD who maintained the remission stage achieved with ADA therapy during pregnancy and delivered her first baby at maturity without any congenital malformations or neurological abnormalities. To the best of our knowledge, this is the first report in Japan of the use of ADA therapy in a patient with CD during pregnancy. Direct exposure to anti-TNF- $\alpha$ treatment during pregnancy is not associated with a higher incidence of adverse pregnancy outcomes than inflammatory bowel disease overall (11). ADA, a pregnancy category B drug, is also an IgG1 antibody and should therefore have a placental transfer rate similar to that of IFX (10). However, there is little evidence of the placental transfer of ADA to the fetus during pregnancy, although there is a case report describing the placental transfer of IFX during the latter period of pregnancy in which high infliximab levels in the serum of the infant were likely due to the occurrence of placental transfer, not breastfeeding (12). There are case reports documenting the successful use of ADA to treat $\mathrm{CD}$ during pregnancy, including one in which 
Table. Laboratory Findings on Admission

\begin{tabular}{lll}
\hline Haematology & & \\
White blood cells (WBC) & $8,900 / \mu \mathrm{L}$ & $3,000 / \mu \mathrm{L} \leq$ normal range $\leq 8,500 / \mu \mathrm{L}$ \\
Red blood count (RBC) & $481 \times 10^{4} / \mu \mathrm{L}$ & $378 \times 10^{4} / \mu \mathrm{L} \leq$ normal range $\leq 499 \times 10^{4} / \mu \mathrm{L}$ \\
Hemoglobin (Hb) & $10.5 \mathrm{~g} / \mathrm{dL}$ & $10.8 \mathrm{~g} / \mathrm{dL} \leq$ normal range $\leq 14.9 \mathrm{~g} / \mathrm{dL}$ \\
Hematocrit (Ht) & $34.60 \%$ & $35.6 \% \leq$ normal range $\leq 45.4 \%$ \\
Platelet (Plt) & $468 \times 10^{3} / \mu \mathrm{L}$ & $150 \times 10^{3} / \mu \mathrm{L} \leq$ normal range $\leq 361 \times 10^{3} / \mu \mathrm{L}$ \\
Erythrocyte sedimentation rate (ESR) & $40 \mathrm{~mm} / \mathrm{h}$ & normal range $\leq 16 \mathrm{~mm} / \mathrm{h}$ \\
& & \\
Serum biochemistry & & \\
Albumin & $4.3 \mathrm{~g} / \mathrm{dL}$ & $4.0 \mathrm{~g} / \mathrm{dL} \leq$ normal range $\leq 5.0 \mathrm{~g} / \mathrm{dL}$ \\
Aspartate amino transferase (AST) & $13 \mathrm{U} / \mathrm{L}$ & $13 \mathrm{U} / \mathrm{L} \leq$ normal range $\leq 33 \mathrm{U} / \mathrm{L}$ \\
Alanine transaminase (ALT) & $8 \mathrm{U} / \mathrm{L}$ & $6 \mathrm{U} / \mathrm{L} \leq$ normal range $\leq 27 \mathrm{U} / \mathrm{L}$ \\
$\gamma$-Glutamyl transpeptidase $(\gamma-\mathrm{GTP})$ & $10 \mathrm{U} / \mathrm{L}$ & $10 \mathrm{U} / \mathrm{L} \leq$ normal range $\leq 47 \mathrm{U} / \mathrm{L}$ \\
Blood urea nitrogen (BUN) & $8 \mathrm{mg} / \mathrm{dL}$ & $8 \mathrm{mg} / \mathrm{dL} \leq$ normal range $\leq 22 \mathrm{mg} / \mathrm{dL}$ \\
Creatinine (Cre) & $0.5 \mathrm{mg} / \mathrm{dL}$ & $0.4 \mathrm{mg} / \mathrm{dL} \leq$ normal range $\leq 0.7 \mathrm{mg} / \mathrm{dL}$ \\
Total bilirubin (T.Bil) & $0.5 \mathrm{mg} / \mathrm{dL}$ & $0.3 \mathrm{mg} / \mathrm{dL} \leq$ normal range $\leq 1.2 \mathrm{mg} / \mathrm{dL}$ \\
Total cholesterol & $202 \mathrm{mg} / \mathrm{dL}$ & $128 \mathrm{mg} / \mathrm{dL} \leq$ normal range $\leq 219 \mathrm{mg} / \mathrm{dL}$ \\
Triglyceride (TG) & $94 \mathrm{mg} / \mathrm{dL}$ & $30 \mathrm{mg} / \mathrm{dL} \leq$ normal range $\leq 149 \mathrm{mg} / \mathrm{dL}$ \\
Natrium (Na) & $138 \mathrm{mEq} / \mathrm{L}$ & $138 \mathrm{mEq} / \mathrm{L} \leq$ normal range $\leq 146 \mathrm{mEq} / \mathrm{L}$ \\
Potassium (K) & $4.2 \mathrm{mEq} / \mathrm{L}$ & $3.6 \mathrm{mEq} / \mathrm{L} \leq$ normal range $\leq 4.9 \mathrm{mEq} / \mathrm{L}$ \\
Chlorine $(\mathrm{Cl})$ & $103 \mathrm{mEq} / \mathrm{L}$ & $99 \mathrm{mEq} / \mathrm{L} \leq$ normal range $\leq 109 \mathrm{mEq} / \mathrm{L}$ \\
Calcium $(\mathrm{Ca})$ & $10.2 \mathrm{mEq} / \mathrm{L}$ & $8.7 \mathrm{mEq} / \mathrm{L} \leq$ normal range $\leq 10.3 \mathrm{mEq} / \mathrm{L}$ \\
C-reactive protein $(\mathrm{CRP})$ & $2.52 \mathrm{mg} / \mathrm{dL}$ & normal range $\leq 0.30 \mathrm{mg} / \mathrm{dL}$ \\
\hline
\end{tabular}

the patient received weekly dosing throughout pregnancy for a total of 38 doses $(10,13-16)$. The Organization of Teratology Information Specialists (OTIS) has reported the findings of 33 women enrolled in a prospective study of ADA in pregnancy and an additional 89 pregnant women who were exposed to ADA and listed in a registry $(16,17)$. The rate of spontaneous abortion $(4 / 33,12.1 \%)$ and stillbirth $(0 / 29)$ was similar to that observed in disease control $(3 / 54,5.6 \%)$ and the general population $(2 / 50,4.0 \%)(16,17)$. The rates of congenital malformation $(2 / 29,6.9 \%)$ and preterm delivery were also within the expected ranges in the non-disease controls $(2 / 43,4.7 \%)(16,17)$. In the present case, the remission of the patient's CD was maintained with ADA therapy during pregnancy, and the patient's first baby was delivered at 39 weeks and two days (female, birth weight: 3,020 $\mathrm{g}$, length: $51 \mathrm{~cm}$ ) without any congenital malformations or neurological abnormalities.

Regarding the elemental diet, a randomized controlled trial demonstrated the effectiveness of a half-elemental diet, which is a promising maintenance therapy for $C D$ patients (1). In the present case, we started a half-ED (900 $\mathrm{kcal} /$ day of Elental ${ }^{\circledR}$ ) in September 2011; however, the patient stopped the ED without permission after two months, which thus led to an exacerbation of abdominal pain and diarrhea.

Regarding the use of corticosteroids in pregnancy, only a marginally increased risk (OR 3.0, 95\%CI 1.08-8.54) of oral cleft malformations was demonstrated in a meta-analysis after exposure to corticosteroids during pregnancy $(16,18)$. Preterm birth has also been described $(16,19)$. However, in humans, no other increases in congenital malformations have been found $(16,20,21)$. On the other hand, GMA can be effective for inducing remission and improving the quality of life in patients with active $\mathrm{CD}$, especially those with lesions in the colon $(2,22,23)$. In Japan and Europe, GMA is an approved treatment option for patients with active
CD (24) and has few side effects. (2) We previously reported the case of a $\mathrm{CD}$ patient with loss of response to scheduled ADA maintenance therapy for whom combination therapy with adalimumab plus intensive GMA induced a clinical remission (25). We also encountered a patient with CD accompanied by chronic myeloid leukemia (CML) who we successfully treated with a combination of intensive GMA and ADA (2). Intensive GMA at a rate of two GMA sessions per week has been recently shown to be more effective than conventional weekly GMA therapy for the treatment of patients with refractory UC (26). However, the safety of GMA during pregnancy remains unclear in patients with IBD because there are no meta-analysis reports of exposure to GMA during pregnancy. Intensive GMA therapy in particular may influence the circulation dynamics of the unborn baby. In the present case, the patient rejected the additional corticosteroid therapy when she presented with exacerbation of abdominal pain and diarrhea in December 2011. She preferred intensive GMA to conventional weekly GMA, expecting that intensive GMA at a rate of two GMA sessions per week may be more effective than conventional weekly GMA. Therefore, we started intensive GMA therapy (two sessions per week for a total of 10 sessions) in addition to the ADA treatment to alleviate the exacerbation of abdominal pain and diarrhea after informed consent was obtained from the patient. The intensive GMA improved the patient's abdominal symptoms.

In Japan, intravenous IFX and subcutaneous ADA, both of which are TNF- $\alpha$ inhibitors, are approved for the treatment of $\mathrm{CD}(2,27)$. ADA is constructed from a fully human monoclonal antibody that can prevent hypersensitivity, in contrast to infliximab, which is a mouse-human chimeric antibody (2). Infliximab occasionally causes an infusion reaction as an adverse event, while adalimumab rarely causes such reactions (2). In the present case, the patient was allergic to mesalazine and was worried about any adverse events 
the drug might induce. After providing informed consent, she therefore chose ADA as the first TNF- $\alpha$ blocker.

In conclusion, we encountered a patient with $\mathrm{CD}$ in pregnancy who was successfully treated with ADA maintenance therapy and delivered a baby girl without any difficulties. We believe that this is the first report in Japan of the successful use of ADA therapy in a CD patient during pregnancy.

The authors state that they have no Conflict of Interest (COI).

\section{References}

1. Takagi S, Utsunomiya K, Kuriyama S, et al. Effectiveness of an 'half elemental diet' as maintenance therapy for Crohn's disease: a randomized-controlled trial. Aliment Pharmacol Ther 24: 13331340, 2006.

2. Mizoshita T, Tanida S, Kusumoto S, et al. Adalimumab therapy following granulocyte and monocyte adsorptive apheresis in a patient with Crohn's disease accompanied by chronic myeloid leukemia. Clin J Gastroenterol 5: 302-306, 2012.

3. Van Deventer SJ. Tumour necrosis factor and Crohn's disease. Gut 40: 443-448, 1997.

4. Hanauer SB, Sandborn WJ, Rutgeerts P, et al. Human anti-tumor necrosis factor monoclonal antibody (adalimumab) in Crohn's disease: the CLASSIC-I trial. Gastroenterology 130: 323-333; quiz 591, 2006.

5. Watanabe M, Hibi T, Lomax KG, et al. Adalimumab for the induction and maintenance of clinical remission in Japanese patients with Crohn's disease. J Crohns Colitis 6: 160-173, 2012.

6. Ljung $\mathrm{T}$, Thomsen $\mathrm{O}$, Vatn $\mathrm{M}$, et al. Granulocyte, monocyte/ macrophage apheresis for inflammatory bowel disease: the first 100 patients treated in Scandinavia. Scand J Gastroenterol 42: 221-227, 2007.

7. Suzuki Y, Yoshimura N, Saniabadi AR, Saito Y. Selective granulocyte and monocyte adsorptive apheresis as a first-line treatment for steroid naive patients with active ulcerative colitis: a prospective uncontrolled study. Dig Dis Sci 49: 565-571, 2004.

8. Mizushima T, Tanida S, Mizoshita T, et al. A complicated case of tacrolimus-induced rapid remission after cesarean section in the early third trimester for refractory severe ulcerative colitis flaring in the initial period of gestation. Case Rep Gastroenterol 5: 144151, 2011.

9. Tsukada Y, Nakamura M, Nakao M, et al. Therapeutic efficacy of granulocytapheresis in a pregnant woman with severe active ulcerative colits: a case report. J Jpn Soc Dial Therapy 40: 871-875, 2007 (in Japanese, Abstract in English).

10. Mahadevan U, Cucchiara S, Hyams JS, et al. The London Position Statement of the World Congress of Gastroenterology on Biological Therapy for IBD with the European Crohn's and Colitis Organisation: pregnancy and pediatrics. Am J Gastroenterol 106: 214-223; quiz 224, 2011.

11. Schnitzler F, Fidder H, Ferrante M, et al. Outcome of pregnancy in women with inflammatory bowel disease treated with antitumor necrosis factor therapy. Inflamm Bowel Dis 17: 1846-1854, 2011.

12. Vasiliauskas EA, Church JA, Silverman N, Barry M, Targan SR, Dubinsky MC. Case report: evidence for transplacental transfer of maternally administered infliximab to the newborn. Clin Gastroenterol Hepatol 4: 1255-1258, 2006.

13. Vesga L, Terdiman JP, Mahadevan U. Adalimumab use in pregnancy. Gut 54: 890, 2005.

14. Mishkin DS, Van Deinse W, Becker JM, Farraye FA. Successful use of adalimumab (humira) for Crohn's disease in pregnancy. Inflamm Bowel Dis 12: 827-828, 2006.

15. Coburn LA, Wise PE, Schwartz DA. The successful use of adalimumab to treat active Crohn's disease of an ileoanal pouch during pregnancy. Dig Dis Sci 51: 2045-2047, 2006.

16. Van Assche G, Dignass A, Reinisch W, et al. The second European evidence-based consensus on the diagnosis and management of Crohn's disease: special situations. J Crohns Colitis 4: 63-101, 2010.

17. Johnson DL, Jones KL, Chambers CD, Sala E. Pregnancy outcomes in women exposed to adalimumab: The OTIS autoimmune diseases in pregnancy project. Gastroenterology 136 (S-1): A-27, 2009.

18. Park-Wyllie L, Mazzotta P, Pastuszak A, et al. Birth defects after maternal exposure to corticosteroids: prospective cohort study and meta-analysis of epidemiological studies. Teratology 62: 385-392, 2000.

19. Norgard B, Hundborg HH, Jacobsen BA, Nielsen GL, Fonager K. Disease activity in pregnant women with Crohn's disease and birth outcomes: a regional Danish cohort study. Am J Gastroenterol 102: 1947-1954, 2007.

20. Mogadam M, Dobbins WO 3rd, Korelitz BI, Ahmed SW. Pregnancy in inflammatory bowel disease: effect of sulfasalazine and corticosteroids on fetal outcome. Gastroenterology 80: 72-76, 1981.

21. Koren G, Pastuszak A, Ito S. Drugs in pregnancy. N Engl J Med 338: 1128-1137, 1998.

22. Fukuda Y, Matsui T, Suzuki Y, et al. Adsorptive granulocyte and monocyte apheresis for refractory Crohn's disease: an open multicenter prospective study. J Gastroenterol 39: 1158-1164, 2004.

23. Matsui $T$, Nishimura $T$, Matake $H$, Ohta $T$, Sakurai $T$, Yao $T$. Granulocytapheresis for Crohn's disease: a report on seven refractory patients. Am J Gastroenterol 98: 511-512, 2003.

24. Nagase K, Fukunaga K, Kashiwamura S, et al. Immunoregulatory effects of adsorptive granulocyte and monocyte apheresis in patients with drug refractory Crohn's disease. Ther Apher Dial 15: 367-373, 2011.

25. Ozeki K, Tanida S, Mizushima T, et al. Combination therapy with adalimumab plus intensive granulocyte and monocyte adsorptive apheresis induced clinical remission in a Crohn's disease patient with the loss of response to scheduled adalimumab maintenance therapy: a case report. Intern Med 51: 595-599, 2012.

26. Sakuraba A, Motoya S, Watanabe K, et al. An open-label prospective randomized multicenter study shows very rapid remission of ulcerative colitis by intensive granulocyte and monocyte adsorptive apheresis as compared with routine weekly treatment. Am J Gastroenterol 104: 2990-2995, 2009.

27. D'Haens GR, Panaccione R, Higgins PD, et al. The london position statement of the world congress of gastroenterology on biological therapy for ibd with the european crohn's and colitis organization: When to start, when to stop, which drug to choose, and how to predict response? Am J Gastroenterol 106: 199-212; quiz 213, 2011.

(C) 2013 The Japanese Society of Internal Medicine http://www.naika.or.jp/imonline/index.html 